\title{
HYDROCARBON PROSPECTING OVER ‘OK’ FIELD, NIGER DELTA USING PETROPHYSICAL AND SEISMIC ATTRIBUTES ANALYSIS
}

\author{
0. Ologe ${ }^{1}$, A. S. Bankole ${ }^{2, *}$ and A. S. Oke ${ }^{1,3}$ \\ 1,2 DePaRTMENT OF ChEMICAL AND GEOLOGICAL SCIENCES, AL-HIKMAH UNIVERSity, ILORIN, NIGERIA. \\ ${ }^{3}$ INSTITUTE FOR GROUNDWATER STUDIES, UNIVERSITY OF FREE STATE, BlOEMFONTEIN, SOUTH AFRICA \\ E-mail addresses:1 toyin.ologe@gmail.com, 2 bayus4sure2@yahoo.com, ${ }^{3}$ sedoeko@yahoo.com
}

\begin{abstract}
Reservoir evaluation of "OK" field in southwestern offshore Niger Delta was carried out with a view to identify the lithological units and quantify the hydrocarbon within the reservoir using an interplay among petrophysics, seismic and structural analyses. To achieve these aims, the work involved analysing and interpreting seismic attributes and the geometry of the identified reservoir sands which consequently led to the determination of the reservoir characteristics. It was deduced that the lithological units were shales and sandstones which occur as an intercalation and with a rhythmic structure. The shale to sand ratio increased with depth. Two hydrocarbonbearing reservoirs were delineated on well logs namely; reservoir $R_{1}$ and $R_{2}$. Hydrocarbon saturation and porosity estimates in the reservoirs; $R_{1}$ and $R_{2}$ were very high varying between 0.6 and 0.75 and 0.21 to 0.27 respectively. Amplitude analysis showed that most structural highs coincided with zones of anomalous amplitude (seismic anomalies). In terms of structure, 3-D structural interpretation revealed that "OK" field is characterized by a rollover anticline, with a closed trapping mechanism for the D series and fault/dip trapping mechanism in the $E$ series. Hence the reservoir units within the field are porous and with substantial hydrocarbon that were well trapped.
\end{abstract}

Keywords: Reservoirs, Fault, Hydrocarbon, Seismic, Amplitudes, Structures

\section{INTRODUCTION}

Petroleum resources remain vital to the economy of several nations of the world, but the enormous cost of exploitation makes interpretation of exploratory data with a high level of precision indispensable in petroleum production [1]. At the exploration stage Petroleum Geoscientist needs to establish the minimum five critical ingredients that are associated with petroleum accumulation; the source rock, thermal maturity, reservoir, trap and seal. The significant of well articulated exploration data in petroleum prospecting necessitated this work; involving petrophysical evaluation and seismic interpretation within the Niger Delta.

The Niger-Delta is one of the world's major hydrocarbon provinces with proven ultimate recoverable reserves of approximately 26 billion bbl of oil and a vast gas resources [2]. The basin remains the most explored in terms of oil and gas with a numerous acquired wireline and seismic data.
The ease to find reservoirs are decreasing rapidly while the need for oil and gas is increasing [3]. There are difficulties in finding smaller, more subtle reservoirs with higher risks and costs. Also, drilling within this hydocarbon province has shown that the presence of structural anomalies does not guarantee successful hydrocarbon production. These have called for quantitative seismic interpretation rather than the initial qualitative seismic approach [4]. An integration of petrophysical and seismic attributes analyses has become a key strategy in quantitative seismic interpretation [5]. A broad multidisciplinary and integrated approach is required for a thorough quantitative assessment of petroleum prospect areas [6]. Therefore a comprehensive interpretation of the field with a suite of software that enhance imaging the complex seismic attributes within the subsurface is needed especially for hydrocarbon mapping. In the light of these, this work is focused towards identifying potential reservoirs using petrophysical analysis and inferences, assessment of hydrocarbon prospective 
areas using seismic attributes; and to describe the geometry of the identified reservoirs.

\section{GEOLOGY OF THE AREA}

The study area covers an area of approximately $41 \mathrm{~km}^{2}$ which is located within the offshore southwestern, Niger Delta (Figure 1). The Niger Delta province has one identified petroleum system which is referred to as Akata-Agbada petroleum system [7]. The stratigraphic units in chronological order are; Akata, Agbada and Benin Formations [8]. The Akata Formation is the oldest which unconformably rest on a Precambrian Basement Complex. It is made up of mostly marine shale and it is the main source rock in the basin. The Akata Formation is overlain by Agbada Formation which is characterised by sandstone and shale. With increasing depth, the volume of the shale tends to increase relative to the sand volume. The Agbada Shale is the main reservoir rock in the Niger Delta, though it might also serve as a secondary source rock due to its shale content. The Benin Formation is the youngest and it overlies the Agbada Formation and it is typical of coastal sands.

\section{MATERIALS AND METHODS}

The data set for this study included soft copy data of 3D seismic volume, composite well logs comprising gamma ray, resistivity, density and neutron logs from two wells. Schlumberger's Petrel software was used to interpret the data. The interpretation procedure involved integration of well logs with seismic data, seismic structural analysis, seismic attributes analysis and petrophysical analysis. Gamma-ray log measures natural radioactivity in formations [9], therefore enabling qualitative identification of zones of shale (interpreted from high gamma readings) and sand (low gamma readings). Identification of hydrocarbon bearing zones was done following the concept of [10]; using deep resistivity log (LLD). Reservoir properties of the delineated geologic pay zones such as net reservoir thickness, gross reservoir thickness, porosity, water saturation and hydrocarbon saturations were determined from logs and using relevant equations such as:

$$
\begin{aligned}
S_{w} & =\frac{\left(a R_{w}\right)}{\Phi^{m} R_{t}} \times \frac{1}{\mathrm{n}} \\
S_{h} & =1-\left(S_{w}\right)
\end{aligned}
$$

In (1) and (2), $S_{w}$ is the water saturation of the uninvaded zone (Archie method), $R_{w}$ is the resistivity of formation water at formation temperature, $R_{t}$ is the true resistivity of formation, $\Phi$ is the porosity, a is the tortuosity factor, $\mathrm{m}$ is the cementation exponent, $\mathrm{n}$ is the saturation exponent which varies from 1.8 to 2.5 and $S_{h}$ is the hydrocarbon saturation.

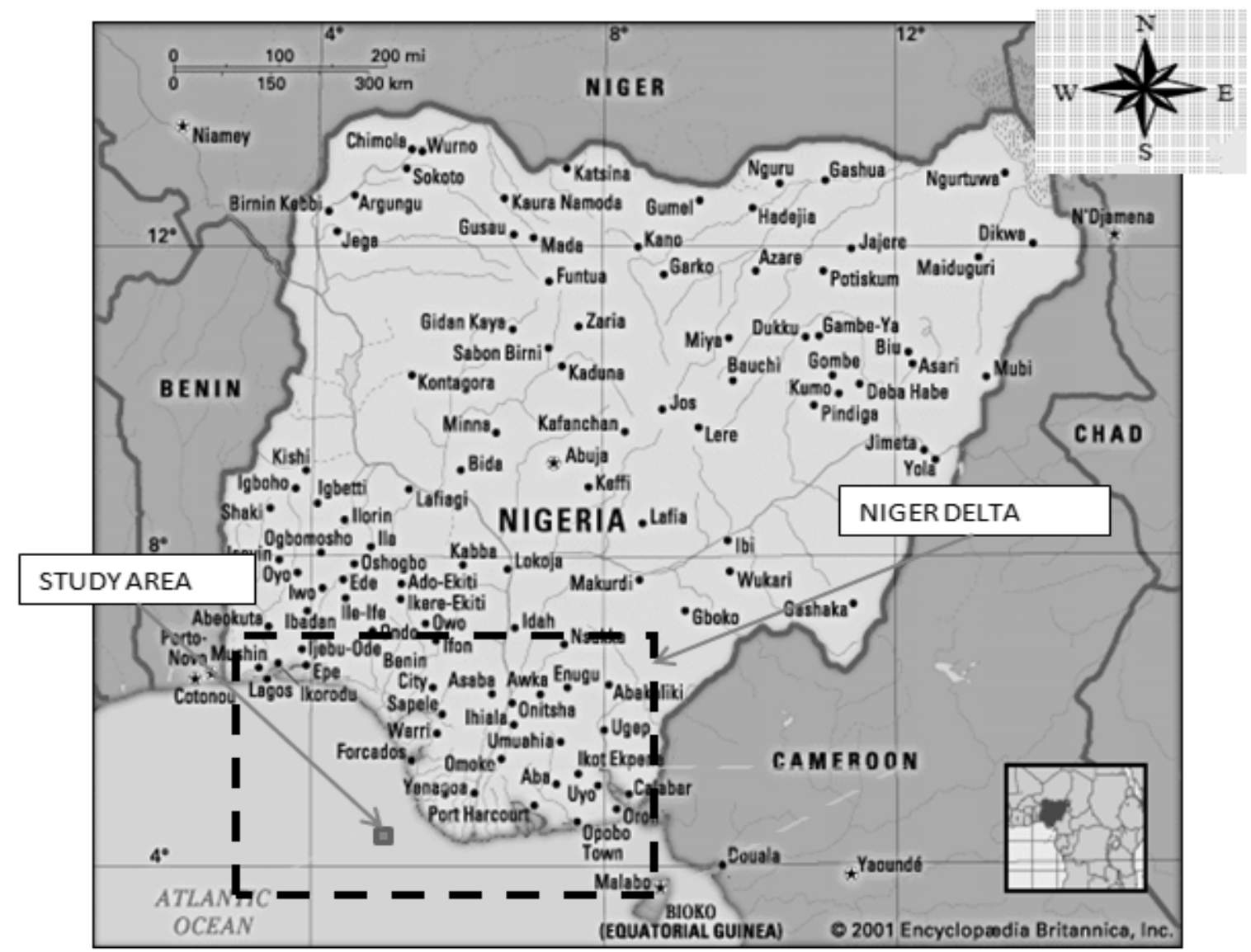

Figure 1: Location Map of Nigeria showing the Niger Delta and the Study Area. 
Porosity values for the identified hydrocarbon reservoirs were estimated using (3):

$$
\Phi=\frac{(\ell \mathrm{ma}-\ell \mathrm{b})}{\ell \mathrm{ma}-\ell \mathrm{f}}
$$

where: $\ell_{\mathrm{b}}$ is the measured bulk density from $\log , \ell_{\mathrm{f}}$ is the fluid density (flushed zone) and $\ell_{\mathrm{ma}}$ is the rock matrix density.

Because of the considerable presence of shale in the reservoirs, the measured porosity was corrected for the volume of shale using [11].

$$
\Phi_{\text {corr }}=\Phi_{d}-V_{s h} \times \Phi_{D s h}
$$

where $\phi$ corr is the shale corrected density porosity, $\phi_{\mathrm{d}}$ is the density porosity, $\mathrm{V}_{\mathrm{sh}}$ is the shale volume and $\phi_{\text {Dsh }}$ is the density porosity of nearby shale.

Well-to-seismic tie of the hydrocarbon reservoirs using check-shot data was done followed by horizon and fault interpretation. Interpretation procedure of the main structural framework can be summarized as follows:

1) Identification of main seismic reflectors, from well ties using checkshots.

2) Manual picking of horizons at this spot on inlines and crosslines. A combination of volume autotracking and interpolation were then used to infill the interpretation.

3) Identification of faults networks (synthetic faults and other related secondary faults) on the seismic sections.
Amplitude extractions were generated for all the interpreted horizons and were superimposed on the structural maps to confirm the presence of hydrocarbon. Vertical and lateral variations in amplitude were analyzed using the horizon slices.

\section{RESULTS AND DISCUSSION}

\subsection{Structural Analysis}

Faults are significant tools in the trapping of hydrocarbon. A growth fault tagged fault A and B (Figure 2) are regional faults with high trapping mechanism. The trapping configurations of the faults along with the embedding shale were presumed to be responsible for the creation of multiple reservoir compartments of hydrocarbon bearing formations that is witnessed from one horizon to the other and this conforms with [12] (Figure 2). The vertical displacement of the major and subsidiary growth faults show that the amount of throw of both major and minor faults are small and varied from line to line in the seismic survey but increases in the northern part of the field for all the horizons considered. Well data were tied to the seismic data after the mapped horizons were digitized and this was done with the aid of synthetic seismogram. The reflections that match the depth to top of the hydrocarbon zones on the well logs were noted. The top of hydrocarbon bearing sand tied with horizon picking started on this reflection (Figure 3).

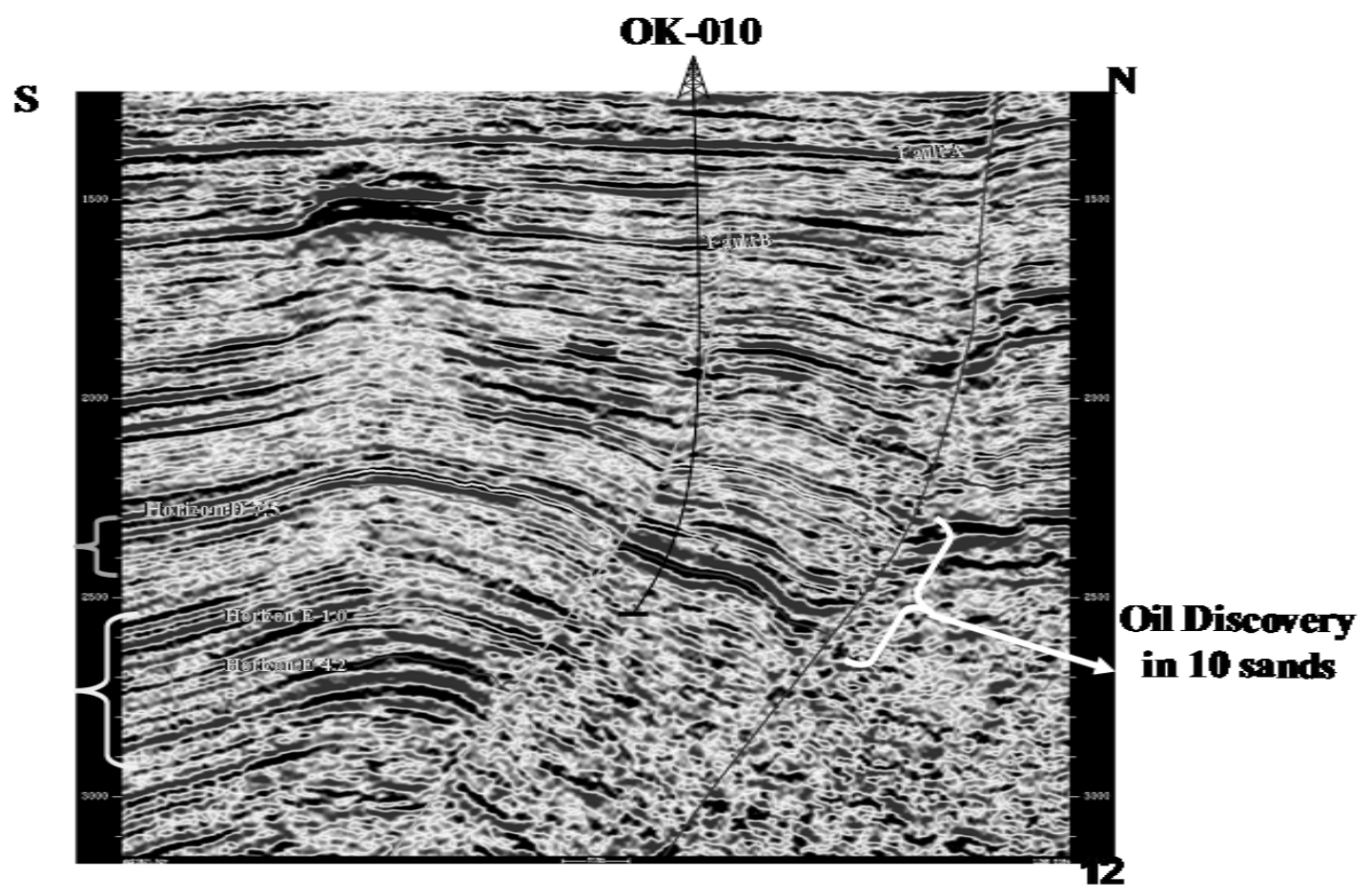

Figure 2: Seismic section showing the picked horizons and the fault types 


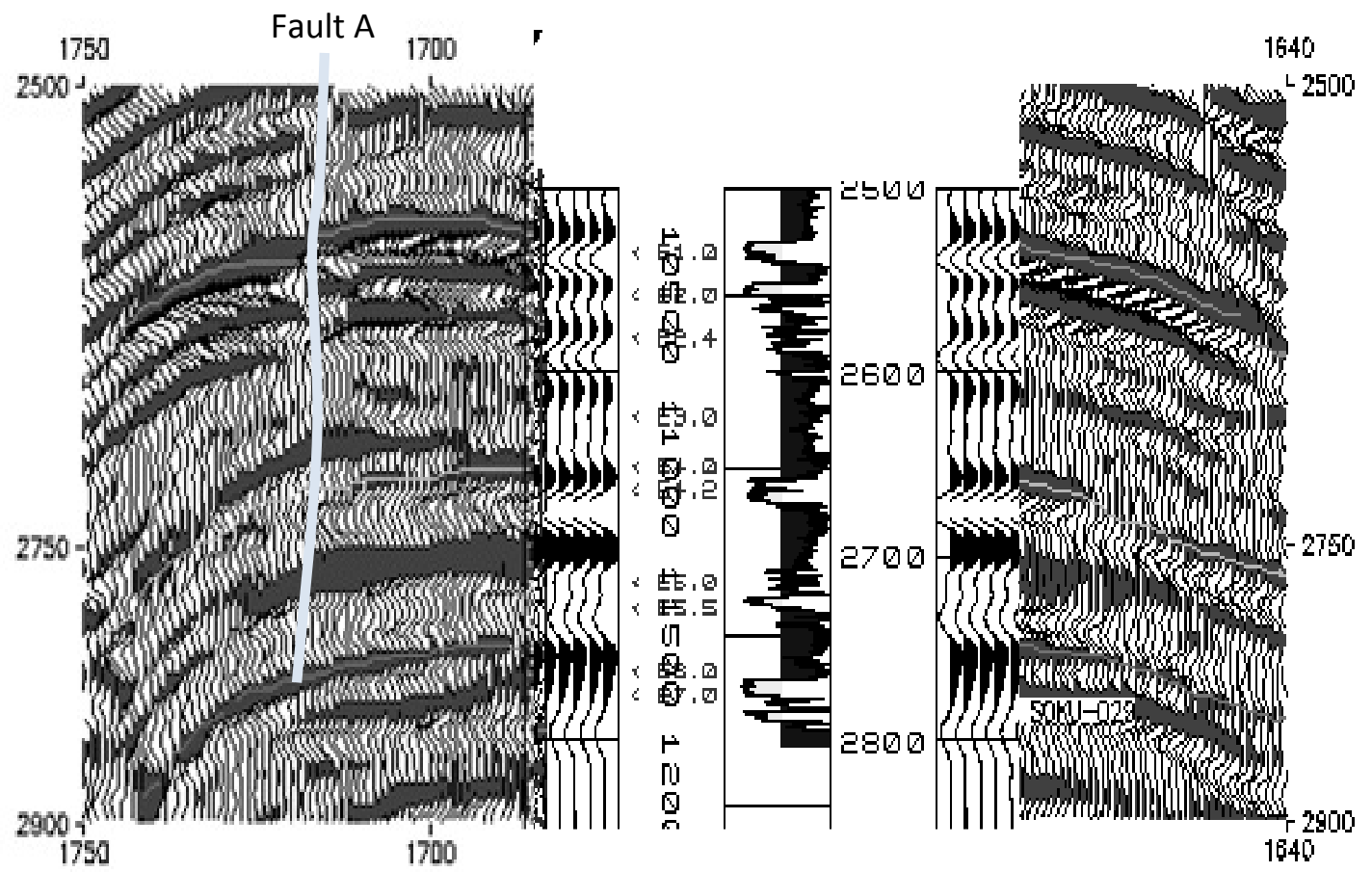

Figure 3: Well to seismic tie from well OK-010.

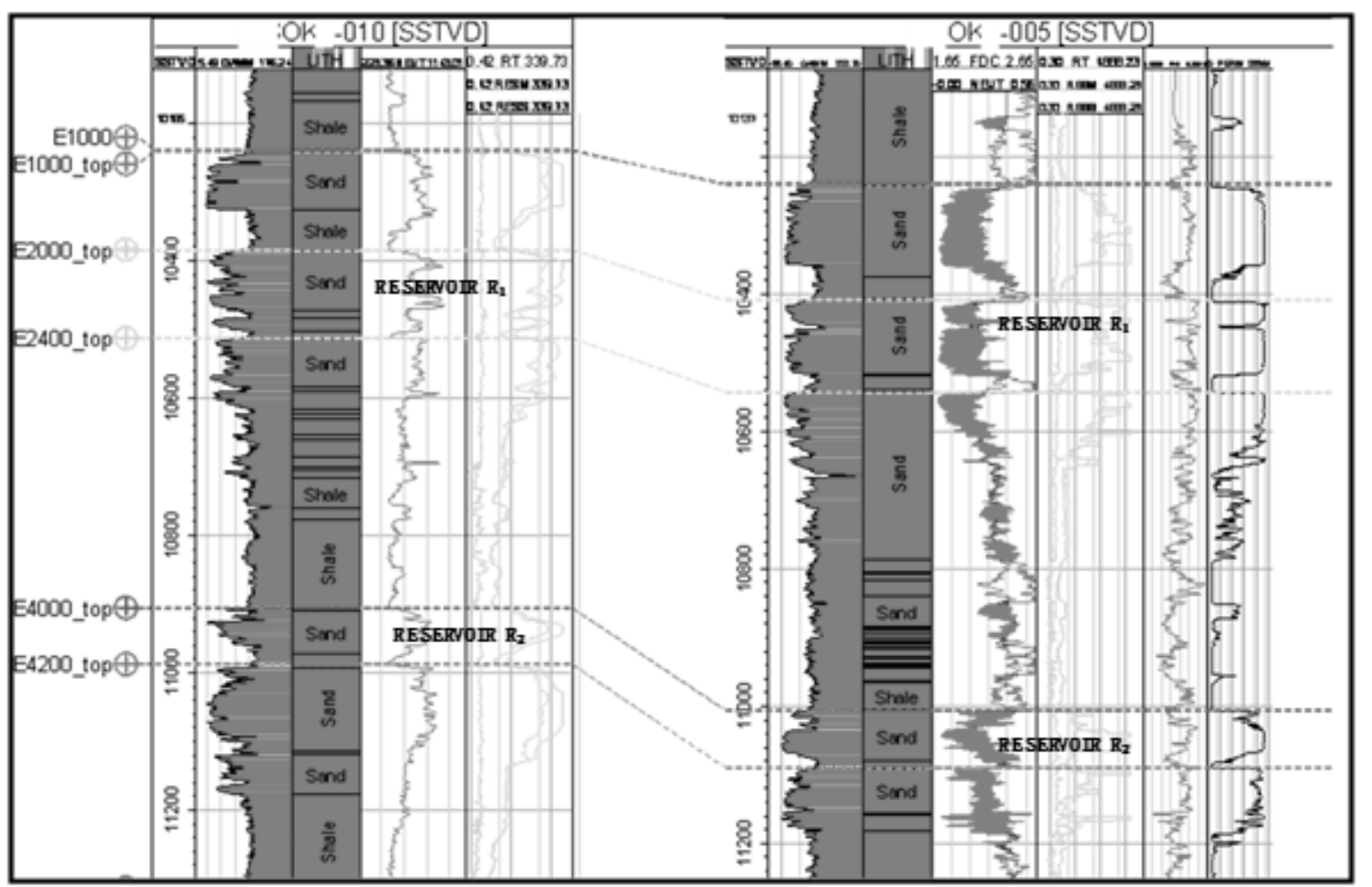

Figure 4: Well log Section showing the reservoirs delineated and correlated across OK-010 and OK-005 Wells.

\subsection{Petrophysical Analysis}

The well log data provided information about the geology of the surrounding formations. The formations of interest in this study were the hydrocarbon bearing formations, hence they were carefully identified and analysed. Interpretation of the lithology shows that the study area is composed of sand-shale intercalations with the shale layers increasing with depth (Figure 4). The lithology panels showed the position of the two reservoirs mapped. The reservoir $R_{1}$ has a gross and a net thickness between 15-27 $\mathrm{m}$, net to gross of 1 and effective porosity value was between 0.21-0.24 while water saturation was 0.15 . The summary of the results obtained from well logs for reservoirs; $\mathrm{R}_{1}$ and $\mathrm{R}_{2}$ were presented in Table 1 and 2 respectively. 
Table 1: Computed Petrophysical Parameters of Reservoirs $R_{1}$

\begin{tabular}{|l|c|c|}
\hline Well & OK 10 & OK 005 \\
\hline Top (m) & 3107 & 3121 \\
\hline Bottom(m) & 3122 & 3148 \\
\hline Thickness (Gross), (m) & 15 & 27 \\
\hline Thickness (Net), (m) & 15 & 27 \\
\hline Net/Gross & 1 & 1 \\
\hline Porosity (effective) & 0.24 & 0.21 \\
\hline Water Saturation & 0.15 & 0.35 \\
\hline
\end{tabular}

Table 2: Computed Petrophysical Parameters of Reservoirs $R_{2}$

\begin{tabular}{|l|c|c|}
\hline Well & OK 10 & OK 005 \\
\hline Top (m) & 3359 & 3390 \\
\hline Bottom(m) & 3388 & 3412 \\
\hline Thickness (Gross), (m) & 28 & 22 \\
\hline Thickness (Net), (m) & 16 & 12 \\
\hline Net/Gross & 0.56 & 0.57 \\
\hline Porosity (effective) & 0.27 & 0.22 \\
\hline Water Saturation & 0.38 & 0.31 \\
\hline
\end{tabular}

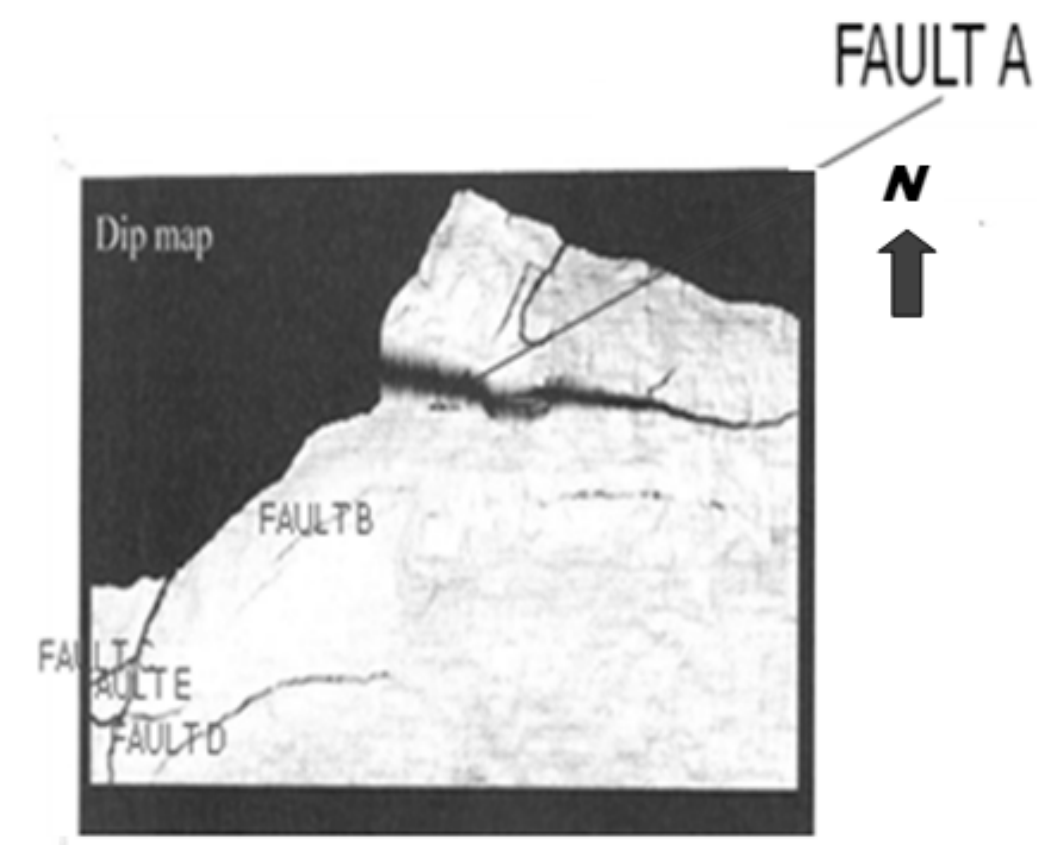

Figure 5: Dip attribute extracted 10ms above E1.0 horizon showing the fault patterns.

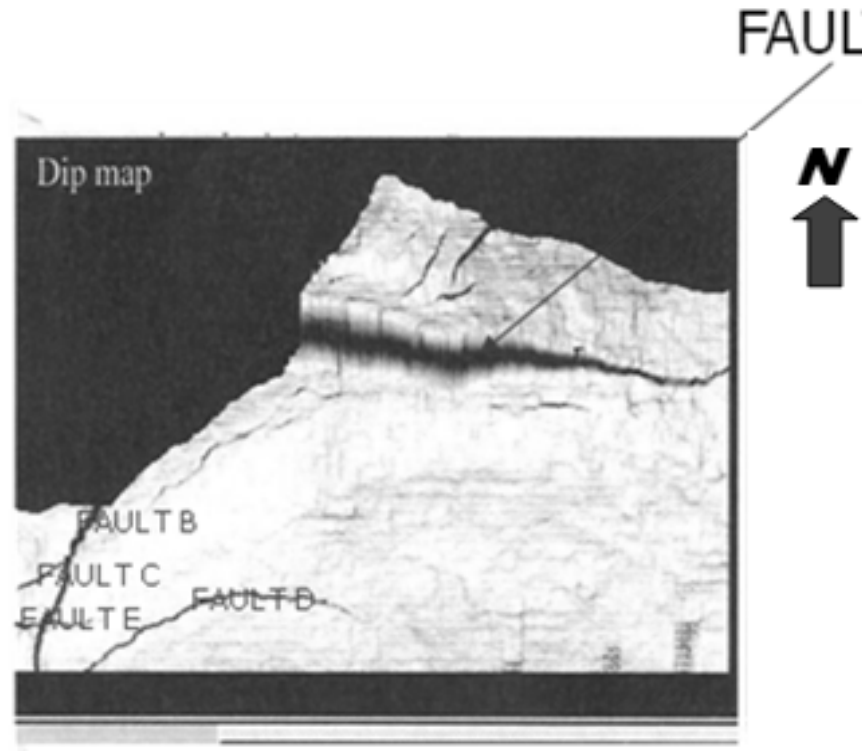

Figure 6: Dip attribute extracted 10ms above E4.2 horizon showing the fault patterns. 
Figure 7 showed an amplitude distribution over horizon E4.2 with depth overlay. The high amplitude zones at the western part of the field correspond to bright spots. The high amplitude zone can also double as the boundaries of the hydrocarbon reservoirs (fluid contact) conform to the structures. Amplitude conforms to the structure and therefore the contacts were better defined and well established which indicated accumulation of hydrocarbon [13]. The seismic amplitude distribution over horizon E1.0
(Figure 8) showed high amplitude zones mostly at the western part corresponding to bright spots. The reflection amplitude conforms to structure, therefore showed the assumed distribution of gas and oil within the field. The contacts were better defined and established. Figure 9 presents the amplitude distribution over horizon D7.5 with depth overlay. The low amplitude zones correspond to dim spot which showed little lateral coverage of the hydrocarbon bearing reservoir.

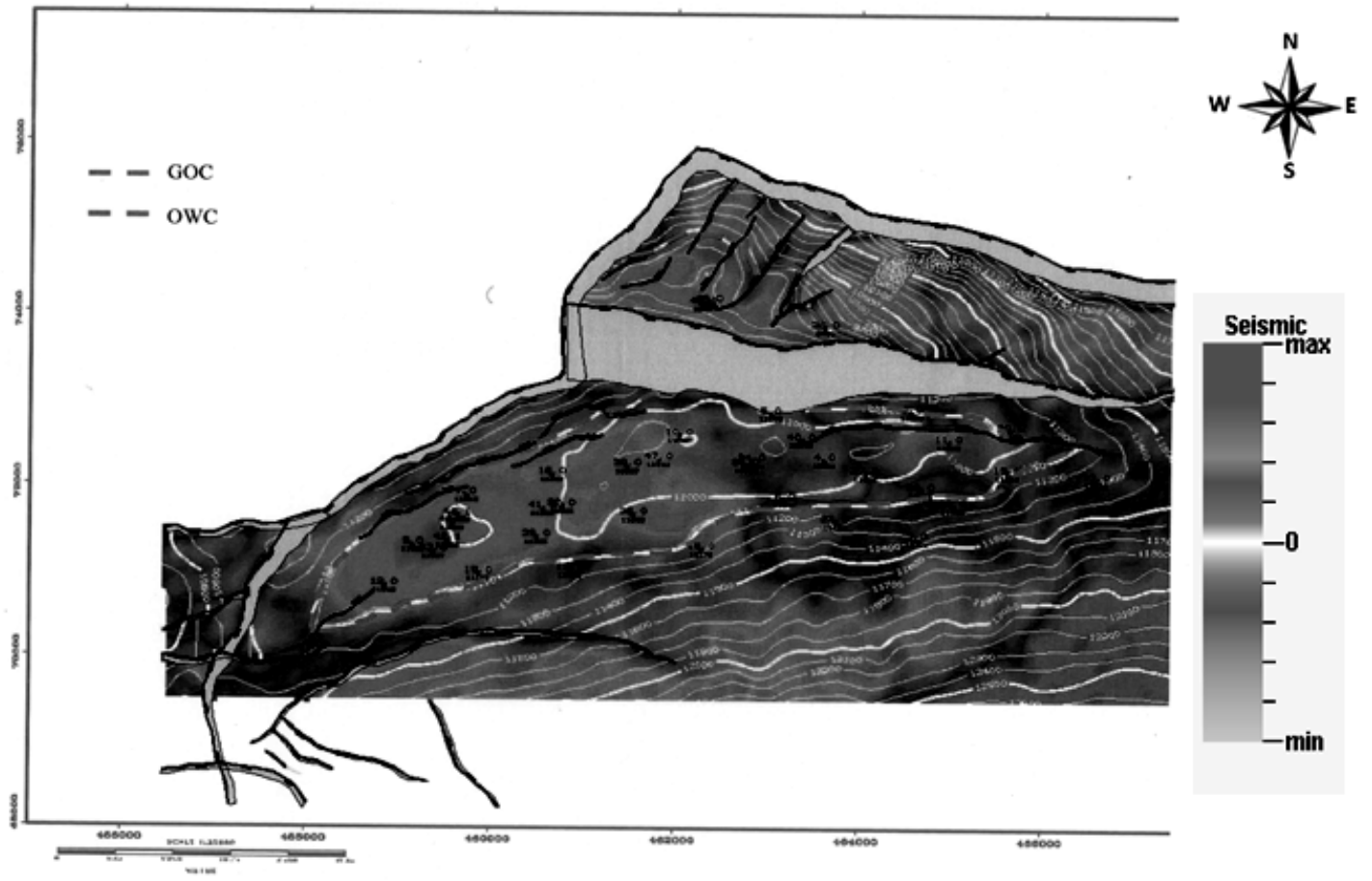

Figure 7: Horizon E 4.2 amplitude with depth overlay.

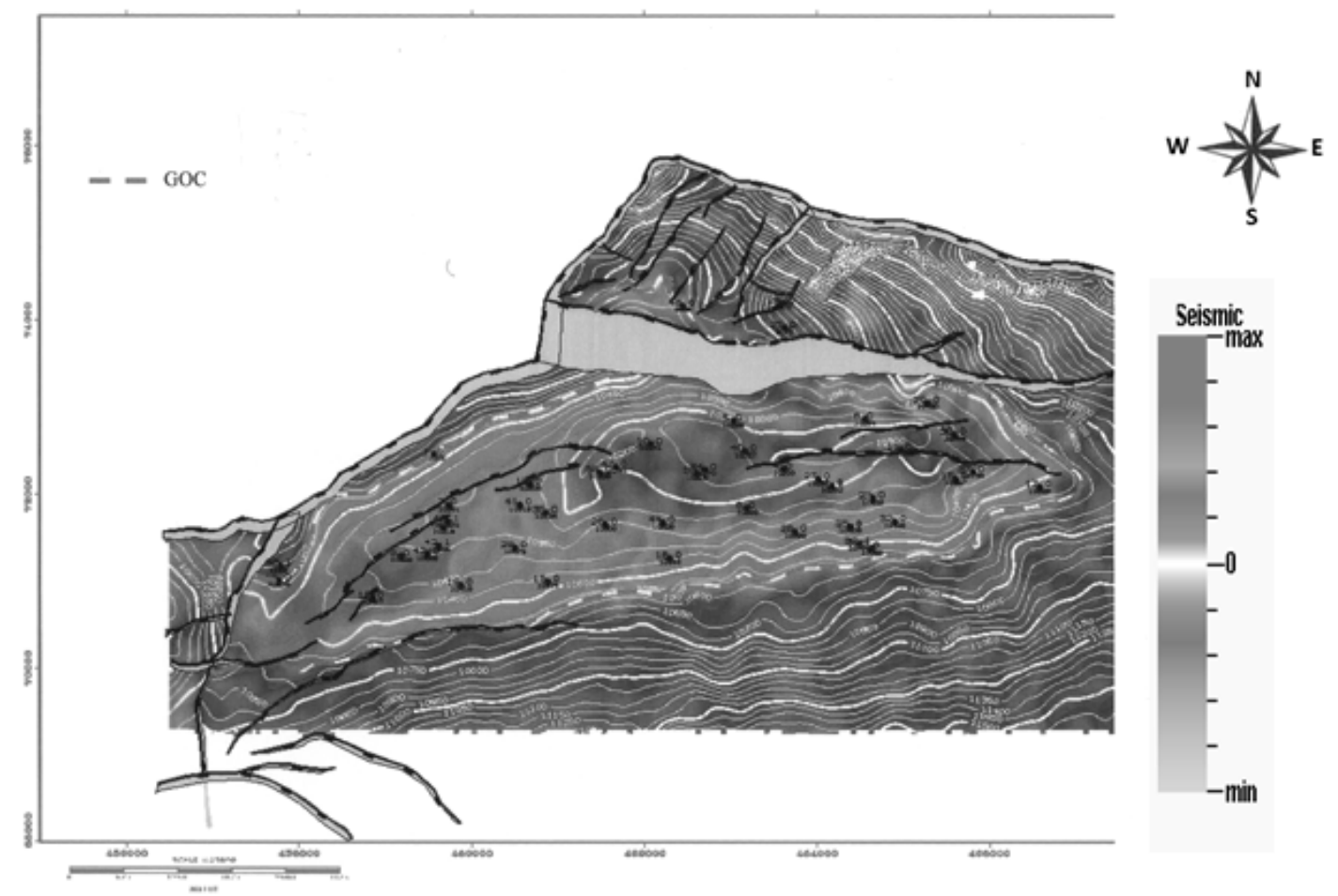

Figure 8: Horizon E 1.0 amplitude with depth overlay. 


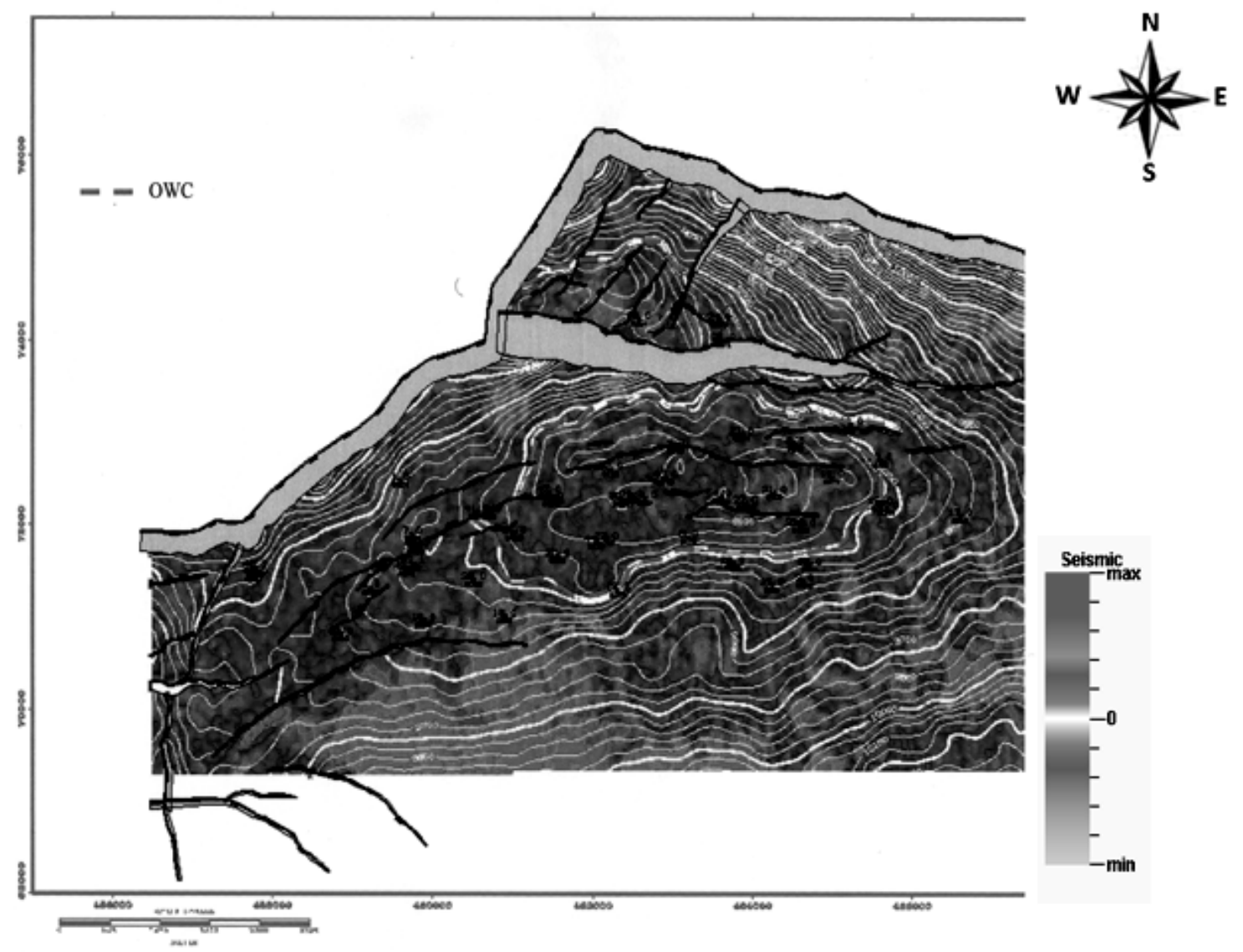

Figure 9: Horizon D 7.5 amplitude with depth overlay.

\section{CONCLUSION}

The subsurface geology and hydrocarbon potential of "OK" field offshore Niger Delta have been studied using 3D seismic, well logs and check-shot survey data. Two hydrocarbon-producing reservoirs were identified. These reservoirs were tagged $R_{1}$ and $R_{2}$ reservoirs. Hydrocarbon saturation and porosity estimates in the two reservoirs were very high ranging from 0.6 to 0.75 and 0.21 to 0.27 respectively. Well to seismic tie showed that hydrocarbon bearing reservoirs tied on the seismic section. Three horizons were studied and two major faults A and B with minor fault $\mathrm{C}, \mathrm{D}$ and $\mathrm{E}$ were mapped for the purpose of carrying out 3-D structural interpretation. This interpretation was further enhanced with dip attribute extracted from 3-D structural interpretation. This was combined with well log analysis in delineating suitable traps for the reservoirs. Attributes maps such as amplitude were extracted to complement the structural interpretation. The amplitude maps for the two horizons (E 1.0 and E 4.2) were similar and zones of high anomalous amplitudes that were associated with structural highs matched with the regions where wells have been drilled. There was a good well synthetic match particularly with zero phased data. Most synthetic seismograms also showed a reflection coinciding with the oil-water contact at most of the matched wells.

There was a strong relationship between the maps as most structural highs coincided with zones of anomalous amplitude. This study was able to show enhancing imaging subsurface reservoirs using seismic attributes.

\section{REFERENCES}

[1] Mbanugo, C.E., Agunwamba, J.C. and Eke, M.N. "Risk Analysis Applied in Oil Exploration and Production", Nigerian Journal of Technology, Vol. 30, Number 2, 2011, pp 73-79.

[2] Ekweozor, C.M. and Okoye, N.V. "Petroleum sourcebed evaluation of Tertiary Niger Delta", American Association of Petroleum Geologists Bulletin, Vol. 64, 1980, pp 1251-1259.

[3] Steiner, W. and Lockhart, J. "Classification and reservoir volume analysis of the upper Wahoo oil field: Internet archive" www.petrobjects.com/ papers.

[4] Brown, A.R. "Interpretation of three-dimensional seismic data", AAPG memoir 42 SEG investigations in geophysics, Vol. 9, 2004, pp 12 -89. 
[5] Phuong, H. Rock physics depth trend analysis using seismic stacking velocity. Unpublished M.Sc. Thesis Department of Earth Science. Norwegian University of Science and Technology, 2006.

[6] Baker Hughes Incorporated. Well site Geology, Baker Hughes INTEQ Training and Development, Baker Hughes INTEQ, 1993.

[7] Adeyanju, O.A. and Olafuyi, O.A. "Experimental Studies of Sand Production from Unconsolidated Sandstone Petroleum Reservoirs in Niger-Delta", Nigerian Journal of Technology, Vol. 30, Number 2, 2011, pp 18-30.

[8] Short, S. and Stauble, G. "Outline of Geology of Niger Delta", American Association of Petroleum Geologists Bulletin, Vol. 51, 1967, pp 761-779.

[9] Schlumberger, Log Interpretation, Principles And Application: Schlumberger Wireline and Testing, Houston, Texas, 1989.
[10] Asquith, G.Basic well log analysis. AAPG methods in exploration series, American Association of Petroleum Geologists, Tulsa, Oklahoma, 2004.

[11]Dewan, J. Essentials of modern open hole log interpretation. Pen well publishing company, Tulsa, Oklahoma, 1983.

[12] Nton, M.E. and Adesina A.D. "Aspects of structures and depositional environment of sand bodies within tomboy field, offshore western Niger Delta, Nigeria" RMZ - Materials and Geoenvironment, Vol. 56, Number 3, 2009, pp 284-303.

[13] Aizebeokhai, A. P. and Olayinka I. "Structural and stratigraphic mapping of Emi field, offshore Niger Delta". Journal of Geology and Mining Research. Vol. 3, Number 2, 2011, pp 25-38. 